\title{
POLYEL - COMPOUND WITH ANTIOXIDANT PROPERTIES
}

\author{
Anastasia ȘTEFÎRȚ $\breve{A}^{1,2^{*}}$, Ion BULHAC ${ }^{1}$, \\ Eduard COROPCEANU ${ }^{3}$, Lilia BRÎNZĂ ${ }^{1,3}$ \\ E-mail: anastasia.stefirta@gmail.com
}

Received: Apr. 07, 2021. Revised: June 18, 2021 Accepted: June 24, 2021. Published online: June 30, 2021

\begin{abstract}
A new complex compound, Polyel, which contains thiourea, macroand microelements in the form of salts and coordination complexes, as well as vitamins, was obtained and tested. Biological tests were performed in laboratory experiments and in the vegetation complex of the Institute of Genetics, Physiology and Plant Protection. As subjects of investigations served the plants Glycine max (Merr) cultivars L. 'Deia', 'Moldovița', and 'Enigma' varieties, grown in the Mitcherlih vegetation pots with a volume of $40 \mathrm{~kg}$ soil and exposed to the drought stress at the phase "flowering - pods formation". The beneficial effect of Polyel on antioxidant protection systems by reducing the accumulation of malondialdehyde (MDA) and intensifying the activity of antioxidant protection enzymes has been established. Polyel has been shown to be one of the new biologically active chemicals that can be used in agriculture to reduce the negative impact of oxidative stress caused by reactive oxygen species (ROS). The use of Polyel as a
\end{abstract}

physiologically active substance (PAS) with antioxidant proprieties for pretreatment of seeds and foliar apparatus is much more effective under moderate drought conditions.

Keywords: Polyel; antioxidant; malondialdehyde; antioxidant protection enzymes; drought; soybean.

\section{INTRODUCTION}

Global warming, the phenomenon of a continuous increase in average atmospheric temperature and obvious reduction in precipitation, is one of the most difficult challenges facing humanity today. Agriculture is one of the most exposed sectors to these changes, being dependent on weather conditions. The complex effects of climate change cause significant qualitative and quantitative loss in annual agricultural production and, in severe cases, can compromise the full yield, such as in 2020. Mitigation of

\footnotetext{
${ }^{1}$ Institute of Chemistry in Chisinau, Republic of Moldova

2 Tiraspol State University in Chisinau, Republic of Moldova

3 Institute of Genetics, Physiology and Plant Protection in Chisinau, Republic of Moldova
} 
the negative effects of extreme natural events and yield stability in agriculture are regarded as top priorities (Murray and Ebi 2012; Jentsch et al., 2011; Krasensky and Jonak, 2012). One of the approaches to increase the crop yield and quality is the use of physiologically active substances (PAS). A wide variety of PAS are involved in regulating the growth and development of plants in unfavorable conditions. The adaptogenic effect of the derivatives of urea - thiourea, diphenylurea, and diphenylthiourea, known as compounds with cytokinin activity, is known. Recent investigations have highlighted the significant effect of pre-treatment of seeds for sowing and foliar apparatus during vegetative growth with thiourea solutions on the biological performance and resistance of maize and soybean plants to conditions of insufficient soil moisture. Thiourea, or thiocarbamide, is a compound that contains nitrogen and sulphur. It has in its composition three functional groups, amino-, imino-, and thiol-, each with an important biological role, which give the compound its antioxidant properties. The high level of substances with hydrogen sulphidric groups and the presence of antioxidants, free radical acceptors, and inhibitors of peroxide reactions in the chain reduces the sensitivity to drought due to the capture of free radicals, inhibition of lipid peroxidation in membranes, etc. The use of thiourea as an agent for pretreatment of seeds and foliar apparatus or as an additional remedy is more effective under stress conditions than under normal conditions (Wahid et al., 2017).

At present, special attention is paid worldwide to such compounds and chemicals, which have a wide spectrum of action, combine properties of physiologically active substances and have trophic effects, are active in low concentrations, and at the same time, increase crop productivity and yield quality. Among the latest PAS generation, the metal coordination complexes with the role of micro- and macroelements, derivatives of natural compounds, which are contained in plants, deserve attention. Numerous investigations have established that they have an influence on plant adaptive properties, which allows the dose of used chemicals and hormones as well as their impact on the environment to be reduced (Ştefîrţă et al., 2012). The importance of these bioactive compounds for agriculture is also evident from the perspective of increasing labor profitability.

Plant dehydration caused by drought is associated with the increased formation of reactive oxygen species (ROS) and oxidative destruction of cellular structures. (Torres et al., 2006). Exogenous application of antioxidants ensures the minimization of ROS production and the diminution of peroxidation of cell membrane lipids. Optimizing the oxidative stress protective capacity under the influence of antioxidants is a consequence of the entire antioxidant enzyme system's activity intensification.

In this context, the aim of the current research was to elucidate the 


\section{Anastasia ȘTEFÎRṬĂ, Ion BULHAC, Eduard COROPCEANU, Lilia BRÎNZĂ}

effect of Polyel, which contains thiourea, macro- and microelements in the form of salts and coordination complexes, as well as vitamins, on the antioxidant protection systems of soybean plants grown in optimal and insufficient moisture conditions.

\section{MATERIALS AND METHODS}

Polyel, obtained in the Institute of Chemistry of the Republic of Moldova (patent MD 1348 Z 2020.02.29, Ștefîrță et al., 2020) was used in this study. Polyel is a solid beige mixture containing thiourea, coordination compounds with biological activity, and macro- and microelements in the following composition, in $\%$ by weight: thiourea $50.00 ; \quad \mathrm{Mg}\left(\mathrm{NO}_{3}\right)_{2} \cdot 6 \mathrm{H}_{2} \mathrm{O} \quad-\quad 20.12$; $\mathrm{Ca}\left(\mathrm{NO}_{3}\right)_{2} \cdot 4 \mathrm{H}_{2} \mathrm{O}$ - 14.51 ; potassium salicylate - 11.41; bis (dimethylglyoxato) selenocarbamidetetrafluoroborate $\mathrm{e}_{1,4}$ (seleni um-selenocarbamide $)_{0,45}(\text { selen-selen })_{0,15}$ cobalt(III) dihydrate; ([Co $\left.\left.(\mathrm{DmgH})_{2}(\mathrm{SeUree})_{2}\right] \mathrm{BF}_{4} \cdot 2 \mathrm{H}_{2} \mathrm{O}\right) \quad-\quad 1.73$; $\left[\mathrm{Fe}_{3} \mathrm{O}\left(\mathrm{CH}_{3} \mathrm{COO}\right)_{6}\left(\mathrm{H}_{2} \mathrm{O}\right)_{3}\right] \mathrm{NO}_{3} \quad \cdot 3 \mathrm{H}_{2} \mathrm{O} \quad-$ $0.69 ; \quad \mathrm{Mn}\left(\mathrm{CH}_{3} \mathrm{COO}\right)_{2} \cdot 4 \mathrm{H}_{2} \mathrm{O} \quad-\quad 0.55$; bis(dimethylglyoxymate)tetrafluoroborate di(nicotinamide)cobalt(III) dihydrate $\left.\left[\mathrm{Co}(\mathrm{DmgH})_{2}(\mathrm{Nia})_{2}\right] \mathrm{BF}_{4} \cdot 2 \mathrm{H}_{2} \mathrm{O}\right) \quad-\quad 0.36$; $\mathrm{Zn}\left(\mathrm{NO}_{3}\right)_{2} \cdot 6 \mathrm{H}_{2} \mathrm{O} \quad$ - $\quad 0.26$; $\left(\mathrm{NH}_{4}\right)_{6} \mathrm{Mo}_{7} \mathrm{O}_{24} \cdot 4 \mathrm{H}_{2} \mathrm{O} \quad$ - $\quad 0.19$; $\left(\mathrm{HOC}_{6} \mathrm{H}_{4} \mathrm{COO}\right)_{2} \mathrm{Cu} \cdot 4 \mathrm{H}_{2} \mathrm{O}-0.16$.

Polyel is a solid beige mixture of coordination complexes of iron(III), cobalt(III), micro- and macroelements, vitamins, and $\mathrm{NO}_{3}{ }^{-}$ions.

The IR spectrum of the solid-state Polyel was measured on a Perkin-Elmer Spectrum-100 FTIR (Fourier Transform Infrared) spectrometer, ATR (Attenuated Total Reflectance) for a spectral range of $4000-650 \mathrm{~cm}^{-1}$ (the range of the measured spectrum) and suspended in vaseline oil 4000-400 $\mathrm{cm}^{-1}$ (PerkinElmer Life \&
Analytikal Sciences, Beaconsfild, UK). The spectrum was interpreted according to recommendations (Bellamy, 1976; Nakamoto, 1963).

The coordination complexes of iron (III) and cobalt (III) were obtained according to the following protocols: $\left[\mathrm{Fe}_{3} \mathrm{O}\left(\mathrm{CH}_{3} \mathrm{COO}\right)_{6}\left(\mathrm{H}_{2} \mathrm{O}\right)_{3}\right] \mathrm{NO}_{3} \cdot 3 \mathrm{H}_{2} \mathrm{O}$

(Mehrota and Bohra, 1983), $\left[\mathrm{Co}(\mathrm{DmgH})_{2}(\mathrm{Nia})_{2}\right] \mathrm{BF}_{4} \cdot 2 \mathrm{H}_{2} \mathrm{O}$ and $\left[\mathrm{Co}(\mathrm{DmgH})_{2}(\mathrm{Se}-\mathrm{Uree})_{2}\right] \mathrm{BF}_{4} \cdot 2 \mathrm{H}_{2} \mathrm{O}$

(Coropceanu et al., 2017), where DmgH is dimethylglyoxime monoanion and Nia is nicotinamide (vitamin PP). The initial substances for the synthesis of the coordination complexes and other components of the Polyel were purchased from SIGMA-ALDRICH and used without further purification.

Biological tests were performed in laboratory experiments and in the vegetation complex of the Institute of Genetics, Physiology and Plant Protection. Plants of Glycine max (L.) Merr., 'Deia', 'Moldovița', and 'Enigma' varieties, obtained in the Research Institute for Field Crops "Selectia", were used in the study.

The effect of plant treatment with PAS on the indices characterizing the intensity of oxidative destruction (malondialdehyde content - MDA) and the activity of antioxidant protection enzymes (superoxide dismutase - SOD, catalase CAT, ascorbate peroxidase - APX, glutathione peroxidase - GPX, gwaiacolpreoxidase - GwPX, glutathione reductase - GR) in soybean leaves was studied in a series of laboratory and vegetation trials.

The laboratory experiments were performed according to the scheme:

Group I - plants grown from seeds treated with water (control);

Group II - plants grown from seeds treated with an aqueous solution of thiourea; 
Group III - plants grown from seeds treated with an aqueous solution of Polyel.

In the vegetation trials, the plants were grown in Mitcherlih containers with a $30 \mathrm{~kg}$ dry soil capacity under controlled moisture conditions. Drought conditions were induced by reducing the watering rate from $70 \%$ of the soil total water capacity (TWC) to $40 \%$ TWC. The duration of water stress was 7 days.

Scheme of vegetation trials: Group I - control, humidity 70\% TWC; Group II drought, humidity 70 - 40\% TWC; Group III - plants treated with thiourea, humidity $70 \%$ TWC; Group IV - plants treated with thiourea, drought 70 - 40\% TWC; Group $\mathrm{V}$ - plants treated with Polyel, humidity 70\% TWC; Group VI - plants treated with Polyel, drought 70 - 40\% TWC.

The testing of the intensity of lipid peroxidation was performed by determining the final product - MDA content. Homogenization of plant material and extraction was as described in (Keshavkant and Naithani, 2010). The activity of antioxidant ferments was expressed in mmol of oxidized substrate and was appreciated as a percentage of the activity of ferments in the leaves of control plants. The activity of key antioxidant protection enzymes was determined by the spectrophotometric method. SOD activity was determined by the protocol (Giannopolitis and Ries, 1977) of inhibiting the photochemical reduction of nitroblue tetrazolium. The conventional unit of SOD activity is considered the activity of the yeast that inhibits $50 \%$ of the photoreduction of nitroblue tetrazolium. CAT activity was estimated according to Chance and Machly (1955) by spectrophotometric determination at $240 \mathrm{~nm}$ of $\mathrm{H}_{2} \mathrm{O}_{2}$ decomposition. APX was determined by monitoring the rate of ascorbate oxidation at $290 \mathrm{~nm}$ (Nacano and Asada, 1981). GR was determined by reducing oxidized glutathione in the presence of NADP.H (Schadle and Bassham, 1977). GPX was determined by measuring at $260 \mathrm{~nm}$ the reduction rate of oxidized glutathione. GwPX - by determining at $470 \mathrm{~nm}$. The intensity of oxidation of guaiacol (2-methoxy-phenol) as a hydrogen donor in the presence of $\mathrm{H}_{2} \mathrm{O}_{2}, 470 \mathrm{~nm}$. The differences between the variants were documented by statistical analysis of the data using the software package "Statistics 7" - ANOVA for PC.

\section{RESULTS AND DISCUSSION}

Polyel should not be interpreted as the bare sum of the initial components due to the possibility of their topochemical interaction during homogenization of the compound. The spectrum is a complex one with some overlapping absorption bands, but many atomic groups in the Polyel's components can be clearly identified and, as a result, it can be used as a reference spectrum in the case of the reproduction of the chemical (Fig. 1). The absorption from $3700-3400 \mathrm{~cm}^{-1}$ is attributed to the $v(\mathrm{OH})$ oscillations of the water with various functions, such as crystallization molecules, ligand, bridge ligand, association molecules, and others. The function of the water molecules is reflected in the IR spectra by moving the absorption bands $v(\mathrm{OH}), \delta(\mathrm{OH})$, etc. The absorption from $3700-3400 \mathrm{~cm}^{-1}$ is attributed to the $v(\mathrm{OH})$ oscillations of the water with various functions, such as: crystallization molecules, ligand, bridge ligand, association molecules and others. The function of water molecules is reflected on IR spectra by moving the absorption bands $v(\mathrm{OH})$, 
$\delta(\mathrm{OH})$, etc. in depending by its concrete role (Nakamoto, 1963).

In the $3600-3000 \mathrm{~cm}^{-1}$ region, there are three absorption bands of high intensity, which can be assigned as follows: 3366 and $3170 \mathrm{~cm}^{-1}$ are $v_{\mathrm{as}}\left(\mathrm{NH}_{2}\right)$ and $v_{\mathrm{s}}\left(\mathrm{NH}_{2}\right)$ of the oscillations of the associated groups of nicotinamide, thiourea, and selenourea, and the band complex at $3273 \mathrm{~cm}^{-1}$ is attributed to the $v(\mathrm{OH})$ oscillations of the respective associated functional groups and $v\left(\mathrm{NH}_{4}{ }^{+}\right)$

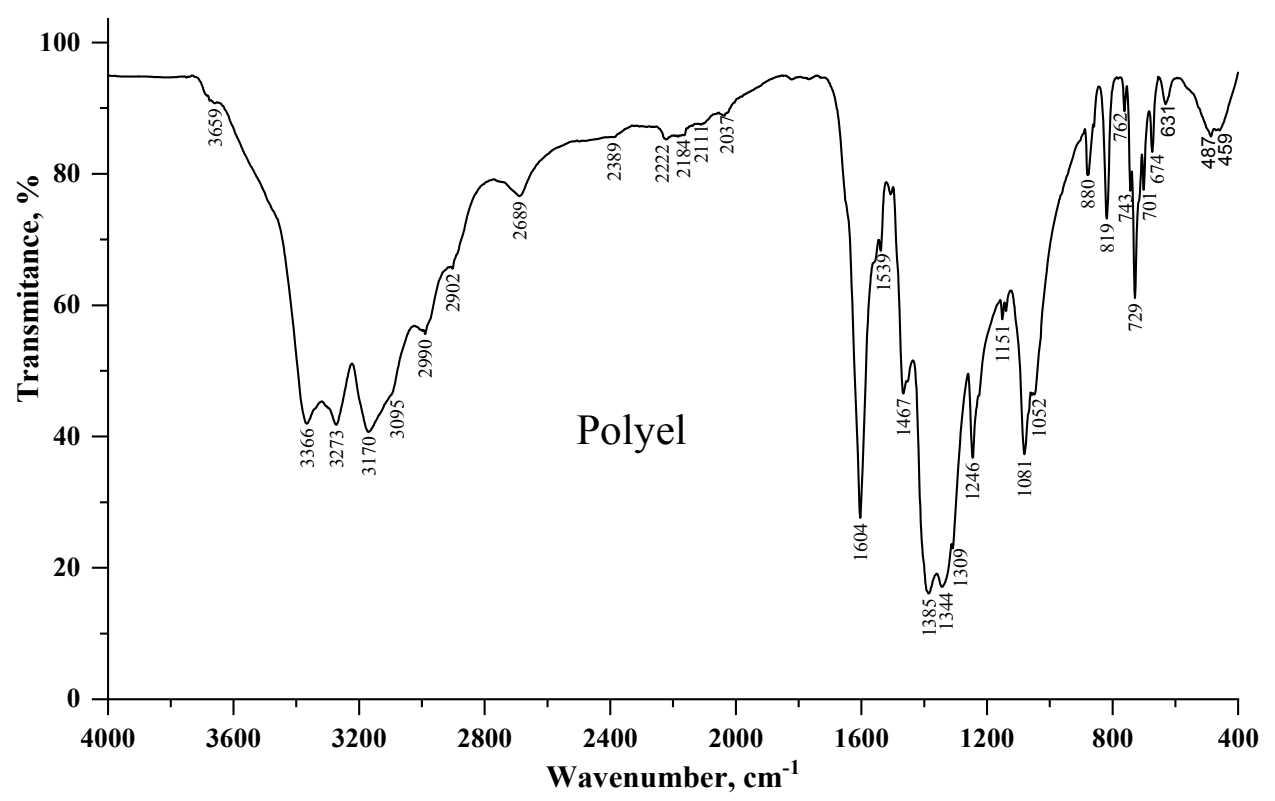

Figure 1 - Polyel IR spectrum

The absorption band at $3095 \mathrm{~cm}^{-1}$ is caused by the $v(\mathrm{CH})$ oscillations in the aromatic rings, and the bands from 2990 and $2902 \mathrm{~cm}^{-1}$ belong to the $v_{\mathrm{as}}(\mathrm{CH})$ and $v_{\mathrm{s}}(\mathrm{CH})$ oscillations in the $\mathrm{CH}_{3}$ groups of the carboxylic acid radicals. The wide band at $2689 \mathrm{~cm}^{-1}$ corresponds to $v(\mathrm{OH})$ oscillations of the $-\mathrm{OH}$ groups, which participate in the formation of strong hydrogen bonds. One of the most intense absorption bands at $1604 \mathrm{~cm}^{-1}$ is attributed to the amide $\mathrm{I}(\mathrm{v}(\mathrm{C}=\mathrm{O}))$ oscillations in nicotinamide. The movement of this band towards the low frequency region proves that it is associated with the formation of hydrogen bonds. The oscillations $\delta_{\text {as }}\left(\mathrm{CH}_{3}\right)$ are expressed in the spectrum by the band at $1467 \mathrm{~cm}^{-1}$. The most intense absorption bands in the 1385 and $1344 \mathrm{~cm}^{-1}$ spectral region represent the oscillations of the uncoordinated $\mathrm{NO}_{3}^{-}$anions, and the absorption band at $1052 \mathrm{~cm}^{-1}$ is assigned to the oscillations of the uncoordinated $\mathrm{BF}_{4}^{-}$anions. DmgH anions are manifested in the spectrum 


\section{POLYEL - COMPOUND WITH ANTIOXIDANT PROPERTIES}

by the absorption bands 1246 and $1081 \mathrm{~cm}^{-1}$, which represent $v_{\text {as }}\left(\mathrm{NO}_{3}{ }^{-}\right)$ and $v_{\mathrm{s}}\left(\mathrm{NO}_{3}{ }^{-}\right)$, respectively.

In the $900-400 \mathrm{~cm}^{-1}$ spectral region, the most intense bands are caused by $\delta(\mathrm{CH})_{\text {non-planar }}$ oscillations in the aromatic rings, which indicate the type of substitution in them. Thus, the 880 and $819 \mathrm{~cm}^{-1}$ absorption bands characterize the 1,3-substitution type in the benzene molecule, i.e., it represents the nicotinamide molecule, which contains 1 isolated hydrogen atom (band at $880 \mathrm{~cm}^{-1}$ ) and three hydrogen atoms side by side (band at $819 \mathrm{~cm}^{-1}$ ). The salicylic acid molecule represents the 1,2-substituted benzene molecule, which contains four adjacent hydrogen atoms, a fact expressed in the spectrum by the $729 \mathrm{~cm}^{-1}$ absorption band.

Organic farming aims to obtain satisfactory yield via non-polluting means to avoid severely disturbing the balance of the environment. From this aspect, the use of bioactive coordination compounds meets the most important requirements for the latest generation of PAS: low dosage of use, minimal toxicity, complete metabolization in cells, and their metabolic inactivation (Ștefîrță et al., 2005).

The results obtained in this paper showed that untreated soybean plants ('Deia', 'Moldovitsa', and 'Enigma' varieties) differ in the degree of change in their malondialdehyde content and antioxidant enzyme activity. It was established in laboratory experiments (Table 1) that Polyel treatment of seeds and foliar apparatus reduces the formation of malondialdehyde, the final product of oxidative destruction of phospholipids, in the leaves of 'Deia' and 'Enigma' plants by 15.2 and $33.0 \%$, compared to the MDA content in the leaves of control plants.

Compared to the plants pretreated with thiourea, the Polyel ensured a reduction of MDA of 8.1 and $27.4 \%$, respectively, in plants of the Deia and Enigma varieties.

The analysis of the obtained results shows that Polyel stimulates the increase in the activity of antioxidant protection enzymes in soybean plants of 'Deia', 'Moldoviţa', and 'Enigma' varieties by $26.8 \%, 49.5 \%$, and $39.1 \%$, respectively, compared to the activity of the antioxidant enzyme system in the control group and by $9.0 \%, 13.6 \%$, and $13.8 \%$ compared to plants pretreated with thiourea. Following the intensification of the activity of the antioxidant enzymes in leaves, the content of malondialdehyde - the final product of lipid peroxidation by reactive oxygen species, was significantly reduced. The use of the Polyel ensured a decrease in the level of malondialdehyde in 'Deia', 'Moldoviţa', and 'Enigma' by $8.97 \%$, $13.60 \%$, and $7.75 \%$, respectively, compared to the thiourea effect.

Therefore, the plants treated with Polyel possess a significantly higher capacity of antioxidant protection, compared to the plants treated with thiourea and, in particular, to those from the control group.

Under drought conditions, the MDA content in the leaves is $63.18 \%$ higher, compared to the MDA content in the leaves of the control group, 
which were grown permanently under optimal humidity. The investigations revealed the beneficial effect of the exogenous administration of thiourea and, in particular, of the Polyel on the processes induced by ROS in the leaves both under drought conditions and with sufficient water supply
(Table 2). Thus, under optimal humidity conditions, the net effect of thiourea and Polyel on the MDA content was expressed by a reduction of about $8.1 \%$ and $15.5 \%$, respectively, compared to the MDA level in the leaves of the control plants.

Table 1 - The antioxidant effect of Polyel on the capacity of antioxidant protection of Glycine max (L.) Merr. at the initial stages of ontogenesis

\begin{tabular}{|c|c|c|c|c|c|}
\hline \multirow{2}{*}{ Parameters } & \multirow{2}{*}{$\begin{array}{c}\text { Control } \\
\mathbf{M} \pm \mathrm{m}\end{array}$} & \multicolumn{2}{|c|}{ Thiourea } & \multicolumn{2}{|c|}{ Polyel } \\
\hline & & $M \pm m$ & $\Delta, \% \mathrm{M}$ & $M \pm m$ & $\Delta, \% \mathbf{M}$ \\
\hline \multicolumn{6}{|c|}{ 'Deia' } \\
\hline $\begin{array}{l}\text { MDA, } \\
\text { mmol g }^{-1} \text { fr. w. }\end{array}$ & $17.44 \pm 0.5$ & $16.03 \pm 0.3$ & -8.08 & $14.79 \pm 0.5$ & -15.20 \\
\hline SOD, conv. un. $g^{-1}$ fr. w. & $68.20 \pm 2.1$ & $74.46 \pm 1.4$ & 9.18 & $82.30 \pm 1.8$ & 20.67 \\
\hline CAT, mmol g ${ }^{-1}$ fr. $w$. & $6.53 \pm 0.2$ & $7.33 \pm 0.1$ & 12.25 & $7.46 \pm 0.2$ & 14.24 \\
\hline APX, mmol g ${ }^{-1}$ fr. $w$. & $8.29 \pm 0.3$ & $10.90 \pm 0.2$ & 31.48 & $13.66 \pm 0.5$ & 64.77 \\
\hline GPX, mmol g ${ }^{-1}$ fr. w. & $51.82 \pm 1.3$ & $60.58 \pm 1.0$ & 16.90 & $62.67 \pm 1.3$ & 20.94 \\
\hline GR, mmol g ${ }^{-1}$ fr. w. & $39.29 \pm 1.2$ & $58.12 \pm 1.0$ & 47.92 & $59.77 \pm 1.0$ & 52.12 \\
\hline GwPX, mmol g ${ }^{-1}$ fr. w. & $121.42 \pm 2.7$ & $132.28 \pm 3.2$ & 8.94 & $148.81 \pm 2.4$ & 22.56 \\
\hline \multicolumn{6}{|c|}{ 'Moldoviţa' } \\
\hline MDA, mmol g ${ }^{-1}$ fr. $w$. & $13.93 \pm 0.4$ & $12.65 \pm 0.4$ & -9.19 & $10.56 \pm 0.3$ & -24.20 \\
\hline SOD, conv. un. $\mathrm{g}^{-1} \mathrm{~m}^{2}$ & $82.93 \pm 2.4$ & $131.98 \pm 3.9$ & 59.15 & $148.48 \pm 4.3$ & 79.04 \\
\hline CAT, mmol g ${ }^{-1}$ fr. w. & $4.48 \pm 0.1$ & $5.46 \pm 0.1$ & 21.87 & $6.14 \pm 0.2$ & 37.05 \\
\hline APX, mmol g ${ }^{-1}$ fr. $w$. & $4.73 \pm 0.2$ & $7.40 \pm 0.2$ & 56.45 & $8.62 \pm 0.3$ & 82.64 \\
\hline GPX, mmol g ${ }^{-1}$ fr. w. & $46.10 \pm 1.3$ & $6.91 \pm 1.9$ & 34.29 & $62.67 \pm 1.9$ & 35.94 \\
\hline GR, mmol g ${ }^{-1}$ fr. w. & $49.20 \pm 1.5$ & $62.74 \pm 1.9$ & 27.52 & $82.22 \pm 2.5$ & 67.11 \\
\hline GwPX, mmol g ${ }^{-1}$ fr. w. & $103.34 \pm 3.1$ & $113.16 \pm 3.4$ & 9.50 & $125.56 \pm 3.8$ & 21.50 \\
\hline \multicolumn{6}{|c|}{ 'Enigma' } \\
\hline MDA, mmol $\mathrm{g}^{-1}$ fr. $w$. & $25.77 \pm 0.7$ & $18.72 \pm 0.5$ & -27.36 & $17.27 \pm 0,5$ & -33.0 \\
\hline SOD, conv. un. $\mathrm{g}^{-1}$ fr. w. & $116.33 \pm 3.5$ & $137.63 \pm 4.1$ & 18.31 & $166.05 \pm 5.0$ & 42.69 \\
\hline CAT, $\mathrm{mmol} \mathrm{g}^{-1}$ fr. w. & $3.62 \pm 0.1$ & $3.99 \pm 0.1$ & 10.22 & $4.74 \pm 0.1$ & 30.94 \\
\hline APX, mmol g ${ }^{-1}$ fr. $w$. & $3.11 \pm 0.1$ & $4.19 \pm 0.1$ & 34.73 & $4.78 \pm 0.5$ & 53.70 \\
\hline GPX, mmol g ${ }^{-1}$ fr. w. & $52.58 \pm 1.6$ & $60.58 \pm 1.8$ & 15.21 & $68.01 \pm 1.8$ & 29.34 \\
\hline GR, mmol g ${ }^{-1}$ fr. w. & $31.04 \pm 0.9$ & $50.52 \pm 1.5$ & 62.75 & $56.44 \pm 1.7$ & 81.81 \\
\hline GwPX, mmol g ${ }^{-1}$ fr. w. & $104.89 \pm 3.1$ & $124.01 \pm 3.7$ & 18.23 & $131.24 \pm 3.9$ & 25.12 \\
\hline
\end{tabular}


POLYEL - COMPOUND WITH ANTIOXIDANT PROPERTIES

Table 2 - The influence of plant treatment with Polyel on the antioxidant protection capacity of Glycine max (L.) Merr. 'Deia' variety plants under drought conditions

\begin{tabular}{|c|c|c|c|c|c|}
\hline \multirow{2}{*}{ Parameters } & \multirow{2}{*}{$\begin{array}{c}\text { Control } \\
\mathrm{M} \pm \mathrm{m}\end{array}$} & \multicolumn{2}{|c|}{ Thiourea } & \multicolumn{2}{|c|}{ Polyel } \\
\hline & & $M \pm m$ & $\Delta, \% \mathbf{M}$ & $M \pm m$ & $\Delta, \% \mathbf{M}$ \\
\hline $\begin{array}{l}\text { MDA, } \\
\text { mmol g }^{-1} \text { fr. } w .\end{array}$ & $\frac{17.44 \pm 0.3^{*}}{28.46 \pm 0.2^{* *}}$ & $\frac{16.03 \pm 0.2}{18.93 \pm 0.4}$ & & $\frac{14.79 \pm 0.3}{17.61 \pm 0.5}$ & \\
\hline $\begin{array}{l}\text { SOD, } \\
\text { un. conv. } g^{-1} \text { fr. w. }\end{array}$ & $\frac{6.20 \pm 0.6}{81.66 \pm 1.4}$ & $\frac{74.46 \pm 0.08}{96.46 \pm 1.6}$ & 18.12 & $\frac{82.30 \pm 2.1}{109.64 \pm 1.2}$ & 34.26 \\
\hline $\begin{array}{l}\text { CAT, } \\
\text { mmol g }^{-1} \text { fr. w. }\end{array}$ & $\frac{6.53 \pm 0.1}{8.14 \pm 0.2}$ & $\frac{7.33 \pm 0.2}{9.31 \pm 0.1}$ & 14.37 & $\frac{7.46 \pm 0.2}{13.87 \pm 0.4}$ & 70.39 \\
\hline $\begin{array}{l}\text { APX, } \\
\text { mmol g }\end{array}$ & $\frac{8.29 \pm 0.1}{13.12 \pm 0.3}$ & $\frac{10.90 \pm 0.3}{17.80 \pm 0.4}$ & 35.67 & $\frac{13.66 \pm 0.2}{20.32 \pm 0.5}$ & 55.11 \\
\hline $\begin{array}{l}\text { GPX, } \\
\text { mmol g }^{-1} \text { fr. w. }\end{array}$ & $\frac{51.82 \pm 0.9}{68.77 \pm 0.5}$ & $\frac{60.58 \pm 1.3}{76.01 \pm 2.1}$ & 10.53 & $\frac{62.67 \pm 1.1}{78.68 \pm 1.4}$ & 14.41 \\
\hline $\begin{array}{l}\text { GR, } \\
\text { mmol g-1 fr. w. }\end{array}$ & $\frac{39.29 \pm 0.6}{66.37 \pm 0.9}$ & $\frac{58.12 \pm 0.8}{93.78 \pm 2.1}$ & 41.30 & $\frac{59.77 \pm 1.3}{120.52 \pm 2.6}$ & 81.59 \\
\hline $\begin{array}{l}\text { GwPX, } \\
\text { mmol g }^{-1} \text { fr. w. }\end{array}$ & $\frac{121.42 \pm 1.8}{152.43 \pm 2.7}$ & $\frac{132.3 \pm 3.8}{173.1 \pm 5,2}$ & 13.55 & $\frac{148.81 \pm 4.3}{176.71 \pm 3.5}$ & 15.93 \\
\hline
\end{tabular}

* control, optimal humidity $70 \%$ TWC; ** drought, humidity $30 \%$ TWC

Under drought conditions, plant treatment ensured a significant reduction in the impact of water stress on the formation of ROS and peroxidation of lipids in plant organs. Seed and foliar apparatus pretreatment with thiourea and Polyel differed in their reduced MDA content, $33.48 \%$ and $38.12 \%$, respectively, compared to untreated plants (Table 2). It is known that an essential role in the cell protection from oxidative destruction belongs to the enzymatic system, especially superoxide dismutase, which catalyzes the dismutation of superoxide radicals $\left(\mathrm{O}^{*}\right)$. Depending on the intensity of the unfavorable factor, such as drought, SOD activity changes differently under moderate drought, the enzyme activity intensifies, and under longterm drought, the enzyme activity decreases (Ștefîrță et al., 2012).
The data presented in Table 2 show that the lack of moisture conditioned the increase in SOD activity in the leaves of untreated plants by $19.7 \%$, compared to the activity of the enzyme in plant organs under an optimal moisture background. However, the MDA content increased significantly by $63.18 \%$, which demonstrates that for normal activity of the enzymes, a certain degree of hydration is required, which corresponds to data reported in the monograph (Ștefîrță et al., 2017). Exogenous administration of PAS reduced the impact of drought manifested by activation of antioxidant enzymes. Plants that have been pretreated with PAS differ in the activity of antioxidant enzymes under optimal humidity and drought conditions. The trend of SOD, CAT, APX, GPX, GR, and GwPX activity tends to increase, 
especially in plants pre-treated with Polyel.

Therefore, the data obtained in the study lead to the conclusion that Polyel can be classified as a new biologically active chemical complex that can be used in agriculture to reduce the negative impact of oxidative stress caused by reactive oxygen species for the antioxidant protection and the reduction of oxidative destruction processes of plant cellular components under drought conditions. The use of Polyel has the prospect of exogenous regulation of antioxidant protection under conditions of relatively low humidity, which has an impact on crop productivity.

\section{CONCLUSIONS}

Polyel, which contains thiourea, macro- and microelements in the form of salts and coordination complexes, as well as vitamins, is a complex physiologically active compound that possesses antioxidant properties.

The beneficial effect of Polyel on antioxidant protection systems by reducing the accumulation of malondialdehyde (MDA) and intensifying the activity of antioxidant protection enzymes has been established.

Plants treated with Polyel possess a significantly higher capacity of antioxidant protection, compared to plants treated with thiourea and, in particular, plants in the control group.

The results of the investigation suggest that Polyel can be used in agriculture to reduce the negative impact of oxidative stress caused by reactive oxygen species (ROS) for antioxidant protection and to reduce the oxidative destruction of plant cellular components under drought conditions.

Acknowledgement. Research was carried out within the project of the Moldova State Program 20.80009.5007.28 "Elaboration of new multifunctional materials and efficient technologies for agriculture, medicine, technology and the educational system based on metal complexes "s" and "d" with polished ligands", financed by the National Agency for Research and Development

\section{REFERENCES}

Bellamy L.J. (1976). The infrared spectra of complex molecules. Ber. Bunsenges. Phys. Chem., Vol. 1 (3rd. ed.), Auflage, Chapman and Hall Ltd., London 1975, 433 Seiten, 32 Abb., 22 Tabellen, 80(1): 99-100, DOI: $10.1002 /$ bbpc. 19760800121

Chance, B. \& Maehly, A.C. (1955). Assay of catalases and peroxidases. Meth. Enzymol., 2: 764-775, DOI: 10.1016/s0076-6879(55)02300-8

Coropceanu, E.B., Bulhac, I., Shtefyrtse, A.A., Botnar, V.F., Melenchuk, M., Kuligin, E. \& Bourosh, P.N. (2017). Synthesis, crystal structure, and biological properties of the complex [Co(DmgH)2(Seu)1.4(Se-Seu)0.5 (Se2)0.1][BF4]. Russ. J. Coord. Chem., 43(3): 164-171, DOI: 10.11 34/s1070328417030046

Giannopolitis, C.N. \& Ries, S.K. (1977). Superoxide dismutases. Plant Physiol., 59(2): 309-314, DOI: 10.11 04/pp.59.2.309

Jentsch, A., Kreyling, J., Elmer, M., Gellesch, E., Glaser, B., Grant, K., Beierkuhnlein, C. (2011). Climate 


\section{POLYEL - COMPOUND WITH ANTIOXIDANT PROPERTIES}

extremes initiate ecosystemregulating functions while maintaining productivity. J. Ecol., 99(3): 689-702, DOI: $10.1111 / \mathrm{j} .1365-2745.2011 .018$ 17.x

Keshavkant, S. \& Naithani, S.C. (2001). Chilling-induced oxidative stress in young sal (Shorea robusta) seedlings. Acta Physiol. Plant., 23(4): 457-466, DOI: 10.1007/s11738-0010056-3

Krasensky, J. \& Jonak, C. (2012). Drought, salt, and temperature stress-induced metabolic rearrangements and regulatory networks. J. Exp. Bot., 63(4): 15931608, DOI: $10.1093 / \mathrm{jxb} / \mathrm{err} 460$

Mehrota, R.C. \& Bohra, R. (1983). Metal carboxylates. Academic Press, London.

Murray, V. \& Ebi, K.L. (2012). IPCC special report on managing the risks of extreme events and disasters to advance climate change adaptation (SREX). J. Epidemiol. Commun. H., 66(9): 759-760, DOI: 10.1136/jech2012-201045

Nakano Y. \& Asada K., (1981). Hydrogen peroxide is scavenged by ascorbatespecific peroxidase in spinach chloroplasts. Plant Cell Physiol.,
22(5): 867-880, DOI: 10.1093/oxford journals.pcp.a076232

Schaedle, M. \& Bassham, J.A. (1977). Chloroplast glutathione reductase. Plant Physiol., 59(5): 1011-1012, DOI: 10.1104/pp.59.5.1011

Ştefîrţă, A., Botnari, V.F., Brânză, L.M., Bulhac, I.I., Coropceanu, E.B., Bourosh, P.N. \& Chilinciuc, A.I. (2017). Possibilities of increasing the antioxidant properties of garlic plants (Allium sativum L.). Acta Chemica lasi, 25(2): 208-231, DOI: 10.1515/achi-2017-0017

Ștefîrță A., Brînză L., Bulhac I., Coropceanu E., Buceaceaia S., Ionașcu A., Covaci O. (2020). Process for cultivating crop plants. Patent no. MD 1348 Z 2020.02.29, State Agency for Intellectual Protection, Republic of Moldova

Torres, M.A., Jones, J.D.G. \& Dangl, J.L. (2006). Reactive oxygen species signaling in response to pathogens. Plant Physiol., 141(2): 373-378, DOI: 10.1104/pp.106.079467

Wahid, A. (2017). Thiourea: A molecule with immense biological significance for plants. Int. J. Agric. Biol., 19(4): 911-920, DOI: 10.17957/ijab/15.0464 